\title{
Comparative Study between Triple Therapy (Peginterferon /Ribavirin/Sofosbuvir) and Dual Therapy (Simeprevir /Sofosbuvir) in Treatment of Chronic HCV Patients
}

\author{
Adel Awaad', No'omaan El Garem², Tamer E. ELeraky', \\ Hosam A. El Dahrouty 4 \\ ${ }^{1}$ Hepatology, Gastroenterology and Infectious Diseases Department Benha University, Egypt \\ ${ }^{2}$ Internal Medicine Department, Cairo University, Egypt. \\ ${ }^{4}$ Hepatology and Gastroentrology Department, Beni-Suef General Hospital, Beni-Suef, Egypt
}

Corresponding Author Hosam A El Dahrouty

Mobile:002010036443 65

\section{E mail:}

hosamali86@yahoo.co $m$

Key words: $H C V$, triple therapy, dual therapy, side effects, virological response
Background and study aim: Major changes have emerged during the last few years in the treatment of chronic $\mathrm{HCV}$ infection. Several direct acting antiviral agents (DAAs) have been developed showing potent activity with higher rates of sustained virological response. This study shows comparison between triple therapy regimen (Peginterferon/ Ribavirin/ Sofosbuvir) and dual therapy regimen (Simprevir/Sofosbuvir) concerning efficacy and safety for Egyptian patients with chronic HCV infection.

Patients and Methods: This retrospective comparative study included 500 Egyptian patients with chronic HCV infection, randomly selected from BeniSuef centre of treatment of viral hepatitis affiliated to the National committee for control of viral hepatitis $(\mathrm{NCCVH})$. They were classified into two groups; triple therapy group included 250 patients had received pegylated interferon alpha, ribavirin and sofosbuvir for 12 weeks and dual therapy group included 250 patients had received sofosbuvir and simeprevir for 12 weeks. All patients were monitored for treatment safety and efficacy.

Results: In the triple therapy group, mostly observed clinical side effects were; flu like illness (40\% of patients), GI manifestations (20.8\% of patients) and psychological manifestations (10.4\% of patients) while photosensitivity ( $22 \%$ of patients), flu like illness (18.8\% of patients) and GI manifestations ( $4.8 \%$ of patients) were the most frequently occurring clinical adverse effects in dual therapy group. Anemia (62.4\% of patients) and leucopenia (49.6\% of patients) were the mostly observed hematological abnormalities in triple therapy group while hyperbilirubinemia
(38\% of patients) was the mainly observed biochemical abnormality in dual therapy group. In the triple therapy group, the end of treatment response (ETR) rate was 95.6\% while sustained virological response (SVR) rate was $91.2 \%$. In dual therapy group, ETR rate was $95.6 \%$ while SVR rate was $93.6 \%$.

Conclusion: The dual therapy (Simeprevir and Sofosbuvir) regimen is more tolerated than triple therapy (Peginterferon, Ribavirin and Sofosbuvir) regimen for Egyptian patients with chronic HCV infection. There was no statistically significant difference as regard sustained virological response between both triple therapy and dual therapy regimens.

Abbreviations: HCV, hepatitis C virus; HCC, hepatocellular carcinoma; Peg-IFN, pegylated interferon; RBV, ribavirin; DAAs, direct acting antivirals; NCCVH, national committee for the control of viral hepatitis; HBV, hepatitis B virus; CBC, complete blood count; AST, aspartate transaminase; ALT, alanine transaminase; PCR, polymerase chain reaction; FBS, fasting blood sugar; AFP, alpha fetoprotein; ANA, antinuclear antibody; TSH, thyroid stimulating hormone; $\mathbf{H b}_{\mathbf{A 1 C}}$, hemoglobin A1C; ECG, electrocardiogram; GI, gastrointestinal; RVR, rapid virological response; ETR, end of treatment response; SVR, sustained virological response; HCV RNA, hepatitis C virus ribonucleic acid; SPSS, statistical package for social science; WBCs, white blood cells; g/dl, gram per deciliter; mcl, microliter; IU/L, international unit per liter; $\mathbf{m g} / \mathbf{d l}$, milligram per deciliter; OATP, organic anion transporting polypeptide; MRP, multidrug resistance-associated protein. 


\section{INTRODUCTION}

The hepatitis $\mathrm{C}$ virus (HCV) was discovered in 1989 which affects approximately 3\% of the world population, corresponding to about 170 million individuals worldwide, and accounts for about 500000 deaths per year [1]. Egypt is the country which has the highest prevalence of $\mathrm{HCV}$ infection in the world. It is considered the leading cause of chronic liver disease and Hepatocellular carcinoma (HCC) [2].

Pegylated-interferon (Peg-IFN) with Ribavirin (RBV) was the standard therapy for hepatitis C until 2011, but new regimens have evolved. In 2011, the first generation protease inhibitors (Boceprevir and Telaprevir) were approved [3]. In recent years, IFN-based strategies combining direct-acting antivirals (DAAs) with Peg-IFN and RBV were approved. Eventually, as an understanding of the HCV life cycle increases, IFN-free combinations of DAAs have evolved to affect all steps of the HCV life cycle and cure most chronically infected patients [4].

This study evaluates the efficacy and safety of both regimens in treatment of Egyptian patients with chronic $\mathrm{HCV}$ infection.

\section{PATIENTS AND METHODS}

This non-interventional, retrospective comparative study includes 500 Egyptian patients with chronic HCV infection randomly selected from Beni-Suef centre of treatment of viral hepatitis which is affiliated to the National committee for control of viral hepatitis $(\mathrm{NCCVH})$ from October 2014 till November 2015.

\section{Inclusion criteria}

- Patients with chronic HCV infection.

- Age between 18-70 years old.

\section{Exclusion criteria}

- Patients with other causes of chronic liver disease were excluded (e.g. chronic HBV, confirmed autoimmune hepatitis, non alcoholic fatty liver disease, metabolic liver diseases).

- Patients with history of HCC or other malignancies.

- Alcohol consumption (>50 gm/day in men and $40 \mathrm{gm} /$ day in women).

- Decompensated liver cirrhosis.

These patients were classified into two groups; triple therapy group included two hundred and fifty patients had received pegylated interferon alpha [137 patients had received pegylated interferon alpha $2 \mathrm{a}$ in a dose of $180 \mathrm{mcg} /$ week] and [113 patients had received pegylated interferon alpha $2 \mathrm{~b}$ in a dose of $1.5 \mathrm{mcg} / \mathrm{kg} / \mathrm{week}$, ribavirin (1000 mg for patients less than $75 \mathrm{~kg}$ b.w and 1200 mg for patients more than $75 \mathrm{~kg}$ body weight daily) and sofosbuvir $400 \mathrm{mg}$ once daily for 12 weeks and dual therapy group included two hundred and fifty patients had received sofosbuvir $400 \mathrm{mg}$ and simeprevir $150 \mathrm{mg}$ daily for 12 weeks.

All of these patients were subjected to the following after informed consent:

- History taking.

- Complete clinical examination.

- Laboratory investigations:

- Before treatment and every month during the treatment for 3 months: CBC, Serum albumin, AST and ALT, Serum creatinine and Total bilirubin.

- Before the treatment, 4 weeks from the start of the treatment, at the end of the treatment and 12 weeks after the end of the treatment: HCV quantitative PCR.

- Before the treatment only: FBS, AFP, ANA titre, TSH, Pregnancy test for female patients at child bearing period and $\mathrm{HbA} 1 \mathrm{c}$ for diabetics.

- Pelvi-abdominal ultrasonography:

- ECG and fundus examination.

Monitoring of treatment safety:

- Patients receiving simeprevir were instructed to use sun protection creams and limiting sun exposure as mild to moderate photosensitivity might occur.

- History taking for any adverse events specifically about the commonly reported adverse effects as influenza like illness, GI upset, psychological manifestations, pruritus, and photosensitivity, etc.

- Clinical examination was performed for any manifestations suspicious of hepatic decompensation (ascites, jaundice and encephalopathy).

- Liver biochemical profile, complete blood count and serum creatinine were tested every visit.

- Ultrasound examination if ascites was suspected.

\section{Monitoring of treatment efficacy:}

- HCV quantitative PCR was done before starting the treatment, at week 4 from starting treatment (rapid virological response (RVR)), at the end of treatment (end of treatment response (ETR), and at week 12 after the end 
of treatment (sustained virological response (SVR).

- Virological response was considered when HCV RNA is below the lower limit of detection at the end of treatment and after 12 weeks from end of treatment (SVR).

- Treatment failure was defined as:

- Viral non response: HCV RNA persistently above lower limit of detection at end of treatment

- Viral Relapse was defined as confirmed HCV RNA above lower limit of detection during the follow up period for patients who achieved HCV RNA below lower limit of detection at the end of treatment.

The results were collected, arranged in tables and figures and statistically analyzed.

\section{Statistical analysis:}

Data were analyzed using the software, Statistical Package for Social Science (SPSS) version 20, then processed and tabulated. Frequency distribution with its percentage and descriptive statistics with mean values and standard deviation were calculated. Chi-square and t-test were done whenever needed. Probabilities of value ( $p$ value) of less than 0.05 were considered significant.

\section{RESULTS}

\section{Age and sex:}

The mean age of patients of triple therapy group was $49.2 \pm 10.5$ years (135 males $(54 \%)$ and 115 females (46\%)) and the mean age of patients of dual therapy group was $52.6 \pm 12.1$ years (104 males $(41.6 \%)$ and 146 females $(58.4 \%)$ ).

\section{Clinical adverse reactions:}

Pruritus is present in $2.8 \%$ of cases in triple therapy group and absent in dual therapy group, photosensitivity in $22 \%$ of cases in dual therapy group and absent in triple therapy group, flu like illness in $40 \%$ of cases in triple therapy group versus $18.8 \%$ of cases in dual therapy group, GI manifestations in $20.8 \%$ of cases in triple therapy group versus $4.8 \%$ of cases in dual therapy group, psychological manifestations in $10.4 \%$ of cases in triple therapy group and absent in dual therapy group and hair loss in $2.8 \%$ of cases in triple therapy group versus $0.4 \%$ of cases in dual therapy group). There was a statistically significant difference between both groups regarding recorded adverse effects $(\mathrm{p}<0.05)$ (Figure 1$)$.

\section{Laboratory findings:}

In triple therapy group, the mean hemoglobin level was $13.67 \mathrm{~g} / \mathrm{dl}$ before treatment and $11.67 \mathrm{~g} / \mathrm{dl}$ at the end of treatment with statistically significant decrease $(\mathrm{p}<0.05)$, the mean WBCs count was $6138.8 / \mathrm{mcl}$ before treatment and $4149.2 / \mathrm{mcl}$ at the end of treatment with statistically significant decrease $(p<0.05)$ and the mean platelet count $(* 1000)$ was $183.8 / \mathrm{mcl}$ before treatment and $164.2 / \mathrm{mcl}$ at the end of treatment with statistically significant decrease $(\mathrm{p}<0.05)$. In dual therapy group, the mean hemoglobin level was $12.7 \mathrm{~g} / \mathrm{dl}$ before treatment and $12.74 \mathrm{~g} / \mathrm{dl}$ at the end of treatment with statistically non significant increase, the mean WBCs count was $5612.2 / \mathrm{mcl}$ before treatment and $5031 / \mathrm{mcl}$ at the end of treatment with statistically significant decrease $(\mathrm{p}<0.05)$ and the mean platelet count $(* 1000)$ was 155.4 $/ \mathrm{mcl}$ before treatment and $166 / \mathrm{mcl}$ at the end of treatment with statistically significant increase $(\mathrm{p}<0.05)($ Table 1).

In triple therapy group, anemia was observed in $13.2 \%$ of cases before treatment and in $62.4 \%$ of cases at the end of treatment, leucopenia was observed in $6.8 \%$ of cases before treatment and in $49.6 \%$ of cases at the end of treatment, but in dual therapy group, anemia was observed in $40.8 \%$ of cases before treatment and in $28 \%$ of cases at the end of treatment and leucopenia was observed in $16.4 \%$ of cases before treatment and in $12 \%$ of cases at the end of treatment.

There was significant decrease of mean serum AST and ALT levels among both triple therapy and dual therapy groups (mean serum AST in triple therapy group was $63.6 \mathrm{IU} / \mathrm{L}$ before starting treatment and $40.1 \mathrm{IU} / \mathrm{L}$ after 12 weeks from starting treatment and in dual therapy group it was $69.8 \mathrm{IU} / \mathrm{L}$ before starting treatment and 39.8 IU/L after 12 weeks from starting treatment and mean serum ALT in triple therapy group was 57 IU/L before starting treatment and $36.8 \mathrm{IU} / \mathrm{L}$ after 12 weeks from starting treatment and in dual therapy group it was $55.4 \mathrm{IU} / \mathrm{L}$ before starting treatment and $32.9 \mathrm{IU} / \mathrm{L}$ after 12 weeks from starting treatment) $(\mathrm{p}<0.05)$ (Table 2).

In triple therapy group, the mean serum bilirubin was $0.8 \mathrm{mg} / \mathrm{dl}$ before treatment and $0.95 \mathrm{mg} / \mathrm{dl}$ at the end of treatment and in dual therapy group, it was $0.89 \mathrm{mg} / \mathrm{dl}$ before treatment and $1.37 \mathrm{mg} / \mathrm{dl}$ at the end of treatment with statistically significant increase in both groups $(\mathrm{p}<0.05)$ (Table 2). Hyperbilirubinemia in triple therapy group was observed in $3.2 \%$ of cases before treatment and 
in $7.2 \%$ of cases at the end of treatment while in dual therapy group, it was observed in $6 \%$ of cases before treatment and in $38 \%$ of cases at the end of treatment.

\section{Virological response:}

End of treatment response (ETR) was the same in both triple therapy and dual therapy groups
(95.6\%), but there was a non-statistically significant difference between both groups in sustained virological response (SVR) $(91.2 \%$ of cases in triple therapy group versus $93.6 \%$ of cases in dual therapy group) (Figure2).

Table (1): Comparison between the mean values of hemoglobin level (g/dl), WBCs count (/mcl) and platelet count $(/ \mathrm{mcl})$ before and after treatment in triple and dual therapy groups:

\begin{tabular}{|c|c|c|c|c|}
\hline \multicolumn{2}{|c|}{ Variables } & $\begin{array}{c}\text { Before } \\
\text { treatment }\end{array}$ & $\begin{array}{c}\text { After } \\
\text { treatment }\end{array}$ & P value \\
\hline $\begin{array}{c}\text { Mean } \\
\text { hemoglobin } \\
\text { level (g/dL) }\end{array}$ & Triple therapy group(mean $\pm \mathrm{Sd})$ & $13.67 \pm 1.42$ & $11.67 \pm 1.38$ & $<0.001^{*}$ \\
\cline { 2 - 5 } & Dual therapy group(mean $\pm \mathrm{Sd})$ & $12.7 \pm 1.33$ & $12.74 \pm 1.27$ & 0.7 \\
\hline $\begin{array}{c}\text { Mean WBCs } \\
\text { count (/mcl) }\end{array}$ & Triple therapy group(mean $\pm \mathrm{Sd})$ & $6138.8 \pm 1775.3$ & $4149.2 \pm 1243$ & $<0.001^{*}$ \\
\cline { 2 - 6 } & Dual therapy group(mean $\pm \mathrm{Sd})$ & $5612.2 \pm 1817$ & $5031 \pm 1265.6$ & $<0.001^{*}$ \\
\hline $\begin{array}{c}\text { Mean platelet } \\
\text { count }(/ \mathbf{m c l})\end{array}$ & Triple therapy group(mean $\pm \mathrm{Sd})$ & $183.8 \pm 51.1$ & $164.2 \pm 43$ & $<0.001^{*}$ \\
\cline { 2 - 6 } & Dual therapy group(mean $\pm \mathrm{Sd})$ & $155.4 \pm 55.2$ & $166 \pm 55.2$ & $<0.001^{*}$ \\
\hline
\end{tabular}

*p value is considered significant " $\mathrm{p}<0.05 "$

Table (2): Comparison between the mean serum levels of AST, ALT (IU/L) and bilirubin (mg/dl) before and after treatment in triple and dual therapy groups:

\begin{tabular}{|c|c|c|c|c|}
\hline \multicolumn{2}{|c|}{ Variables } & $\begin{array}{c}\text { Before } \\
\text { treatment }\end{array}$ & $\begin{array}{c}\text { After } \\
\text { treatment }\end{array}$ & P value \\
\hline \multirow{2}{*}{$\begin{array}{c}\text { Mean serum } \\
\text { AST (IU/L) }\end{array}$} & Triple therapy group(mean \pm Sd) & $63.6 \pm 35.4$ & $40.1 \pm 13.4$ & $<0.001^{*}$ \\
\cline { 2 - 5 } & Dual therapy group(mean $\pm \mathrm{Sd})$ & $69.8 \pm 43$ & $39.8 \pm 22.5$ & $<0.001^{*}$ \\
\hline \multirow{2}{*}{$\begin{array}{c}\text { Mean serum } \\
\text { ALT (IU/L) }\end{array}$} & Triple therapy group(mean $\pm \mathrm{Sd})$ & $57 \pm 31.7$ & $36.8 \pm 13.8$ & $<0.001^{*}$ \\
\cline { 2 - 6 } Mean serum \\
$\begin{array}{c}\text { Milirubin } \\
\text { (mg/dl) }\end{array}$ & Dual therapy group(mean $\pm \mathrm{Sd})$ & $55.4 \pm 34.5$ & $32.9 \pm 16.4$ & $<0.001^{*}$ \\
\cline { 2 - 6 } & Triple therapy group(mean \pm Sd) & $0.8 \pm 0.28$ & $0.95 \pm 0.42$ & $<0.001^{*}$ \\
\hline
\end{tabular}

*p value is considered significant " $\mathrm{p}<0.05 "$ 


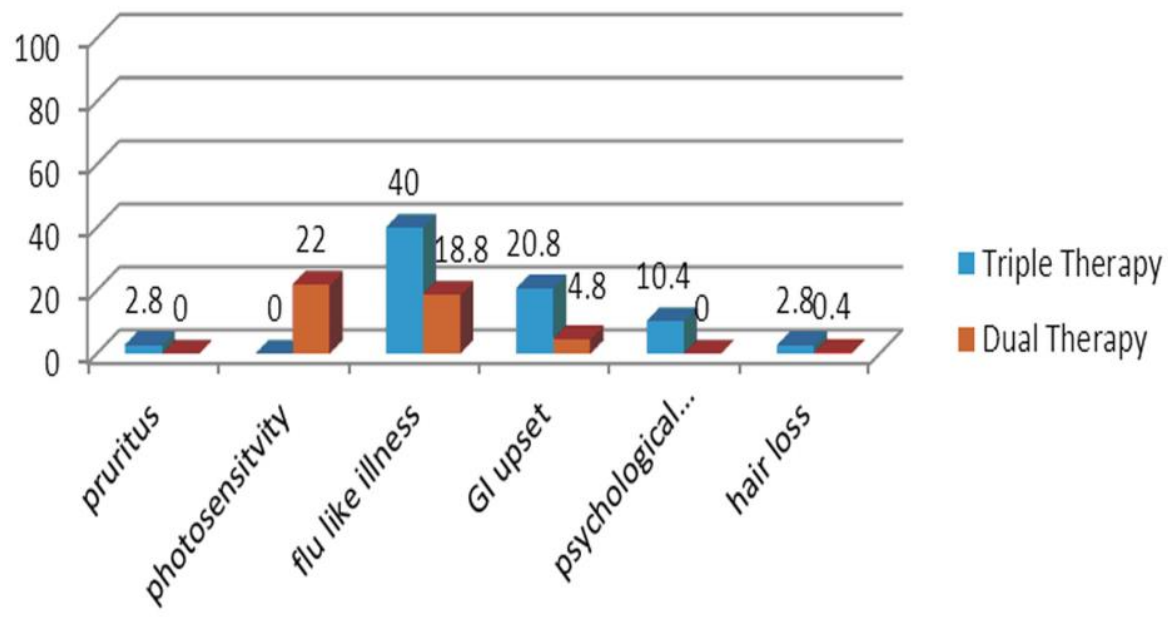

Figure (1): Comparison between Triple and Dual therapy groups regarding clinical adverse effects (\%)

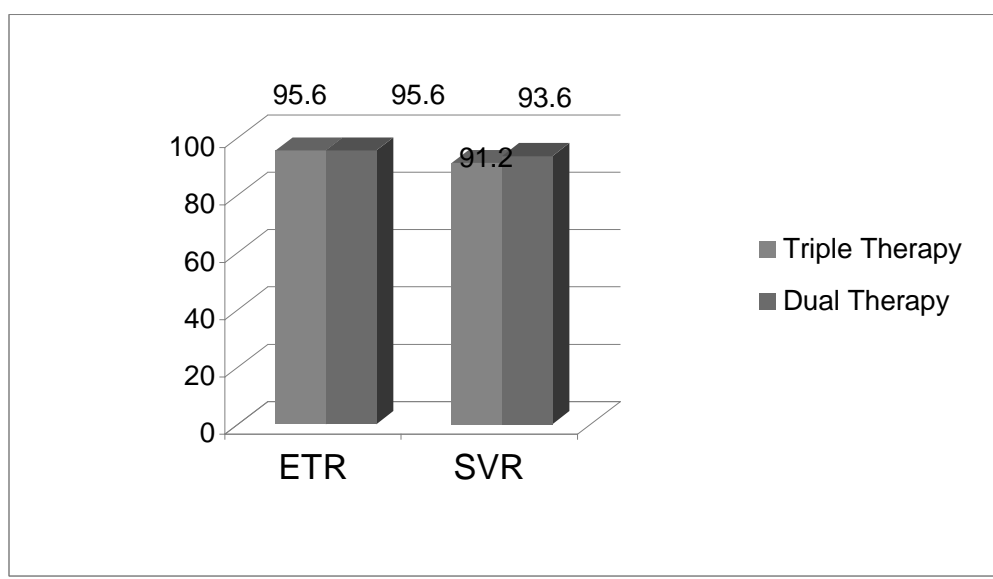

Figure (2): Comparison between Triple and Dual therapy groups regarding virological response $(\%)$

\section{DISCUSSION}

In this study; the clinical adverse effects noticed in patients of the triple therapy group during treatment were: pruritus in $2.8 \%$ of cases, flu like illness (headache, fever, fatigue and malaise) in $40 \%$ of cases, GI manifestations (decreased appetite, nausea and vomiting) in $20.8 \%$ of cases, psychological manifestations (insomnia, irritability, nervousness and depression) in $10.4 \%$ of cases and hair loss in $2.8 \%$ of cases. These data come in agreement with that of Steinebrunner and others [6] who demonstrated that pruritus had been detected in $5 \%$ of cases, flu like illness was detected in $37 \%$ of cases in the form of (headache in $4 \%$, fatigue in $18 \%$, myalgia in $15 \%$ ) psychological manifestations had been detected in $13 \%$ in the form of (aggressiveness in 6\%, insomnia in $3 \%$, depression in $3 \%$ and acute psychosis in $1 \%$ ) and hair loss had been noticed in $10 \%$ of cases and Pearlman and other colleagues [5] who reported GI manifestations in $29 \%$ of their patients.

In dual therapy group, the clinical adverse effects noticed were; flu like illness (headache, fatigue and malaise) in $18.8 \%$ of cases, GI manifestations (anorexia, nausea and vomiting) in $4.8 \%$ of cases, hair loss in $0.4 \%$ of cases and photosensitivity in $22 \%$ of cases. These results are consistent with that reported by Sulkowski and other colleagues [7] who found that flu like illness was noticed in $10.9 \%$ of cases and Modi and others [8] found that GI manifestations in the form of nausea noticed in $10 \%$ of cases [7,8].Photosensitivity reaction in this study was noticed in $22 \%$ of the patients, Pearlman and others [5] and Sulkowski and other colleagues [7] reported that photosensitivity reaction had been noticed in $5 \%$ of cases and $6.8 \%$ of cases respectively [5,7]. This relative disparity in the results of photosensitivity reaction between the current study and other 
studies may be explained by the style of life and job of the patients included in this study as most of them are farmers and workers; they usually spend most of the day time in direct exposure to the sunlight. The variation of clinical adverse effects in different studies may be attributed to different sample sizes, other diseases co morbidity and different lifestyles.

In the present study, the mean hemoglobin level in triple therapy group was significantly decreased at the end of treatment $(13.67 \pm 1.42 \mathrm{~g} / \mathrm{dl}$ before starting treatment $)$ versus $(11.67 \pm 1.38 \mathrm{~g} / \mathrm{dl}$ at the end of treatment). In the dual therapy group; the mean hemoglobin level was increased at the end of treatment $(12.71 \pm 1.33 \mathrm{~g} / \mathrm{dl}$ before starting treatment) versus $(12.74 \pm 1.27 \mathrm{~g} / \mathrm{dl}$ at the end of treatment), but this increase wasn't statistically significant. The mean hemoglobin level at the end of treatment in dual therapy group was significantly higher than that in triple therapy group $(12.74 \pm 1.27 \mathrm{~g} / \mathrm{dl})$ versus $(11.67 \pm 1.38$ $\mathrm{g} / \mathrm{dl}$ ) inspite of that the mean hemoglobin level was significantly higher in triple therapy group than dual therapy group before starting treatment $(13.67 \pm 1.42 \mathrm{~g} / \mathrm{dl})$ versus $(12.74 \pm 1.27 \mathrm{~g} / \mathrm{dl})$. These data clarify that triple therapy regimen has a negative effect on hemoglobin level compared to dual therapy regimen.

The mean WBCs count in both triple therapy and dual therapy group was significantly reduced at the end of treatment; $(6138.8 \pm 1775.3 / \mathrm{mcl}$ before treatment) versus $(4149.2 \pm 1243 / \mathrm{mcl}$ at the end of treatment) and $(5612.2 \pm 1817 / \mathrm{mcl}$ before treatment $)$ versus $(5031 \pm 1265.6 / \mathrm{mcl}$ at the end of treatment) respectively. The mean WBCs count at the end of treatment in dual therapy group was significantly higher than that in triple therapy group $(5031 \pm 1265.6 / \mathrm{mcl})$ versus $(4149.2 \pm 1243$ $/ \mathrm{mcl}$ ) inspite of that the mean WBCs count was significantly higher in triple therapy group than dual therapy group before starting treatment $(5612.2 \pm 1817 / \mathrm{mcl})$ versus $(6138.8 \pm 1775.3 / \mathrm{mcl})$.

The mean platelet count $(* 1000)$ in triple therapy group was significantly decreased at the end of treatment $(183.8 \pm 51.1 / \mathrm{mcl}$ before treatment $)$ versus $(164.2 \pm 43 / \mathrm{mcl}$ at the end of treatment). In dual therapy group; the mean platelet count $(* 1000)$ was significantly increased at the end of treatment $(155.4 \pm 55.2 / \mathrm{mcl}$ before treatment $)$ versus $165.9 \pm 55.2 / \mathrm{mcl}$ at the end of treatment). These results indicate that triple therapy regimen has a negative effect on platelet count compared to dual therapy regimen.
The mean value of serum AST in both triple therapy and dual therapy groups was significantly decreased at the end of treatment; $(63.6 \pm 35.4$ IU/L before starting treatment) versus (40.1 \pm $13.4 \mathrm{IU} / \mathrm{L}$ at the end of treatment $)$ and $(69.8 \pm 43$ IU/L before starting treatment) versus $(39.8 \pm$ $22.5 \mathrm{IU} / \mathrm{L}$ at the end of treatment) respectively. The mean value of serum ALT in both triple therapy and dual therapy groups was significantly decreased at the end of treatment $(57 \pm 31.7 \mathrm{IU} / \mathrm{L}$ before treatment) versus $(36.8 \pm 13.8 \mathrm{IU} / \mathrm{L}$ at the end of treatment) and $(55.4 \pm 34.5 \mathrm{IU} / \mathrm{L}$ before starting treatment $)$ versus $(32.9 \pm 16.4 \mathrm{IU} / \mathrm{L}$ at the end of treatment). These data indicate that both triple therapy and dual therapy regimens improve serum levels of AST and ALT. The mean value of serum total bilirubin in both triple therapy and dual therapy groups was significantly increased at the end of treatment $(0.8 \pm 0.27$ $\mathrm{mg} / \mathrm{dl}$ before starting treatment) versus $(0.95 \pm$ $0.42 \mathrm{mg} / \mathrm{dl}$ at the end of treatment $)$ and $(0.89 \pm$ $0.29 \mathrm{mg} / \mathrm{dl}$ before starting treatment) versus $(1.37 \pm 0.68 \mathrm{mg} / \mathrm{dl}$ at the end of treatment $)$ respectively $(\mathrm{p}<0.05)$.

The data regarding triple therapy group come in agreement with Ibrahim and his colleagues [9] who reported significant decrease of: the mean hemoglobin level $(14.16 \pm 0.27 \mathrm{~g} / \mathrm{dl}$ before treatment) versus $(10.74 \pm 0.21 \mathrm{~g} / \mathrm{dl}$ at the end of treatment), the mean WBCs count $(6620 \pm 370$ $/ \mathrm{mcl}$ before treatment $)$ versus $(3.920 \pm 260 / \mathrm{mcl}$ at the end of treatment), the mean platelet count $(* 1000)(157.2 \pm 9.4 / \mathrm{mcl}$ before treatment $)$ versus $(115.3 \pm 8.2 / \mathrm{mcl}$ at the end of treatment $)$, the mean serum AST $(72.97 \pm 6.55$ IU/L before treatment) versus $(36.17 \pm 3.25 \mathrm{IU} / \mathrm{L}$ at the end of treatment) and the mean serum ALT (65.48 \pm $7.29 \mathrm{IU} / \mathrm{L}$ before starting treatment) versus (32.68 $\pm 3.15 \mathrm{IU} / \mathrm{L}$ at the end of treatment $)(\mathrm{p}<0.05)$, but Ibrahim and his colleagues [9] differ with the present study in the point of mean serum bilirubin which shows no statistically difference before starting treatment and at the end of treatment $(0.89 \pm 0.09 \mathrm{mg} / \mathrm{dl}$ before starting treatment) and $(1.11 \pm 0.14 \mathrm{mg} / \mathrm{dl}$ at the end of treatment) for patients received triple therapy regimen in their study [9].

In the present study in triple therapy group; anemia before treatment was detected in $13.2 \%$ versus $62.4 \%$ of cases at the end of treatment. These data nearly comes in accordance with Steinebrunner and others [6] who demonstrated that anemia was detected in $75 \%$ of cases received triple therapy regimen in their study [6]. But 
Lawitz and his colleagues [10] declared different results regarding percent of occurrence of anemia with triple therapy regimen; they figured that anemia had occurred in $23 \%$ of cases who received triple therapy regimen in their study.

In triple therapy group, Leucopenia in this study was detected before treatment in $6.8 \%$ versus $49.6 \%$ of cases at the end of treatment which comes in disagreement with Wehmeyer and other colleagues [11] who revealed that leucopenia was occurred in $12.5 \%$ of cases.

This relative disparity between results in this study and that of other studies may be due to difference in the cut off values (The cut off value of anemia in this study was (hemoglobin < 11.5 $\mathrm{g} / \mathrm{dL}$ ) while in Lawitz and his colleagues [10] it was (hemoglobin $<10 \mathrm{~g} / \mathrm{dL}$ ) and the cut off value of leucopenia in this study was (WBCs <4000 $/ \mathrm{mcl}$ ) but in Wehmeyer other colleagues [11] it was (WBCs $<2000 / \mathrm{mcl}$ ).

In dual therapy group in the present study; anemia (hemoglobin $<11.5 \mathrm{~g} / \mathrm{dL}$ ) before starting treatment was detected in $40.8 \%$ versus $28 \%$ of cases at the end of treatment and leucopenia was detected in $16.4 \%$ of cases before starting treatment versus $12 \%$ of cases at the end of treatment. This data comes in difference with Modi and others [8] who reported that anemia was recorded in $10 \%$ of cases received dual therapy regimen. Pearlman and others [5] also reported different results; they declared that anemia was recorded in $2 \%$ of cases in received dual therapy regimen $[\mathbf{5 , 8}]$. This relative disparity between the percent of anemia in this study and other studies may be explained by that in this study $40.8 \%$ of patients received dual therapy regimen were anemic before starting treatment.

Hyperbilirubinemia in triple therapy group was detected in $3.2 \%$ of cases before treatment versus $7.2 \%$ of cases at the end of treatment. In dual therapy group; it was detected in $6 \%$ of cases before treatment versus $38 \%$ of cases at the end of treatment. This data comes in agreement with Modi and others [8] who reported that $24 \%$ of patients experienced at least a 2 -fold increase in total bilirubin during treatment with dual therapy regimen [8]. But Pearlman and colleagues [5] reported that hyperbilirubinemia was detected in $7 \%$ of cases included in their study [5]. This relative disparity may be due to the difference in the cut off values of hyperbilirubinemia (in this study (total bilirubin $>1.3 \mathrm{mg} / \mathrm{dl}$ ) while in Pearlman and colleagues [5] it was (total bilirubin $>5$
Upper limit of normal serum total bilirubin level). Increased serum bilirubin levels with simeprevir intake could be attributed to the inhibition of organic anion transporting polypeptide (OATP) 1B1 and multidrug resistance-associated protein (MRP) 2 hepatic bilirubin transporters by simeprevir [12].

In the current study; the end of treatment response (ETR) had been achieved in $95.6 \%$ of cases included in the triple therapy group. This result comes in agreement with that reported by Wehmeyer and other colleagues [11] who declared that $95.8 \%$ of patients had achieved the end of treatment response (ETR).

The present study showed that sustained virological response (SVR) had been achieved in $91.2 \%$ of cases included in the triple therapy group. This data comes in accordance with that of Ibrahim and others [9] who reported that sustained virological response (SVR) had been achieved in $93.55 \%$ of cases who had received triple therapy in their study, also both Kowdley and colleagues [13] and Degasperi and Aghemo [14] revealed that $90 \%$ of cases who received triple therapy regimen in their studies had achieved sustained virological response.

In this study; the end of treatment response (ETR) had been achieved in $95.6 \%$ of cases included in dual therapy group. This data comes in partial accordance with that of El-Khayat and others [15] whose patients totally achieved end of treatment response (ETR).

As regards to sustained virological response (SVR) in dual therapy group in this study, it had been achieved in $93.6 \%$ of cases. This data is nearly similar to that of El Raziky and other colleagues [16] and Eletreby and others [17] who reported that sustained virological response (SVR) had been achieved in $92 \%$ and $94 \%$ of their cases respectively. Similarly, Kwo and colleagues [18] and El-Khayat and other colleagues [15] reported that sustained virological response (SVR) had been achieved in $97 \%$ and $95.7 \%$ of cases who had received dual therapy regimen respectively.

In the present study, sustained virological response was achieved in $91.2 \%$ of patients in triple therapy group while it was achieved in $93.6 \%$ of patients in dual therapy group; the difference was no statistically significant. In contrast to this study, Pearlman and colleagues [5] figured that the dual therapy regimen resulted in a significantly higher 
rate of sustained virological response (SVR) when compared with that of the triple therapy regimen (93\% versus $75 \%$ ) [5]. This relative difference between the current study and the other study regarding SVR in triple therapy group may be attributed to different HCV genotypes which had infected the patients included in both studies; the main HCV genotype in this study is genotype 4 because it is the main prevalent HCV genotype in Egypt, but all patients included in the other study were infected by HCV genotype 1a.

\section{CONCLUSION}

In Egyptian patients with chronic HCV infection who had been included in this study; the dual therapy regimen (Simeprevir/ Sofosbuvir) was more tolerated with less adverse effects than the triple therapy regimen (Pegylated interferon/ Ribavirin/ Sofosbuvir) apart from the occurrence of photosensitivity and mild hyperbilirubinemia in some of patients in dual therapy group. There was no statistical difference as regard sustained virological response between both triple therapy and dual therapy groups with slightly higher sustained virological response rates in dual therapy group than triple therapy group.

Funding: None.

Conflicts of interest: None.

Ethical approval: Approved.

\section{REFERENCES}

1- Wandeler G, Dufour J.F, Bruggmann P, Rauch A. Hepatitis C: a changing epidemic. Swiss Med Wkly; 2015, 145: w14093.

2- El-Zayadi A, Abaza H, Shawky S, Mohamed MK, Selim OE, Badran HM. Prevalence and epidemiological features of hepatocellular carcinoma in Egypt - a single centre experience. Hepatol. Res.; 2001, 19:170-179.

3- Lim SG. Chronic hepatitis $\mathrm{C}$ genotype 1 treatment roadmap for resource constrained settings. World J Gastroenterology; 2015, 21:1972-1981.

4- Zeuzem S, Jacobson I.M, Baykal T, Marinho RT, Poordad $\mathrm{F}$, Bourlière $\mathrm{M}$, et al. Retreatment of HCV with ABT-450/r-ombitasvir and dasabuvir with ribavirin. $N$ Engl J Med.; 2014, 370: 16041614.

5- Pearlman B.L, Ehleben C, Perrys M. The combination of simeprevir and sofosbuvir is more effective than that of peginterferon, ribavirin, and sofosbuvir for patients with hepatitis C -related Child's class A cirrhosis. Gastroenterology; 2015, 148:762-770.

6- Steinebrunner N, Sprinzl M.F, Zimmermann T, Wörns MA, Zimmerer T, Galle PR, et al. Early virological response may predict treatment response in sofosbuvir-based combination therapy of chronic hepatitis c in a multi-center "real-life" cohort. BMC Gastroenterology; 2015, 15:97.

7- Sulkowski M.S, Vargas H.E, Di Bisceglie A.M, Kuo A, Reddy KR, Lim JK, et al. Effectiveness of simeprevir plus sofosbuvir, with or without ribavirin, in real-world patients with $\mathrm{HCV}$ genotype 1 infection. Gastroenterology; 2015, 150(2): 419-429.

8- Modi A, Nazario H, Trotter J, Gautam M, Weinstein J, Mantry P, et al. Safety and efficacy of simeprevir plus sofosbuvir with or without ribavirin in patients with decompensated genotype 1 hepatitis C cirrhosis. Liver Transplantation; 2016, 22:281-286.

9- Ibrahim H, Soliman M, El-Elaimy I, El-Hageen RS. Assessment of immunological, haematological and biochemical status after Sofosbuvir-based combination therapy in HCV Egyptian patients from Menoufia Province. Journal of Applied Pharmaceutical Science; 2016, 6(10): 174-180.

10- Lawitz E, Mangia A, Wyles D, Rodriguez-Torres M, Hassanein T, Gordon SC, et al. Sofosbuvir for previously untreated chronic hepatitis $\mathrm{C}$ infection. New England Journal of Medicine; 2013, 368:1878-87.

11- Wehmeyer M.H, Jordan S, Lüth S, Hartl J, Stoehr A, Eißing C, et al. Efficacy and safety of sofosbuvir-based triple therapy in hepatitis $\mathrm{C}$ genotype 4 infection. Digestive and Liver Disease; 2015, 47: 811-814.

12- Lawitz E, Sulkowski M.S, Ghalib R, RodriguezTorres M, Younossi ZM, Corregidor A, et al. Simeprevir plus sofosbuvir, with or without ribavirin, to treat chronic infection with hepatitis $\mathrm{C}$ virus genotype 1 in non-responders to pegylated interferon and ribavirin and treatmentnaive patients: the COSMOS randomized study. Lancet; 2014, 384 (9956):1756-65.

13- Kowdley K.V, Lawitz E, Crespo I, Hassanein T, Davis MN, DeMicco M, et al. Sofosbuvir with pegylated interferon alfa-2a and ribavirin for treatment-naive patients with hepatitis $\mathrm{C}$ genotype-1 infection (ATOMIC): an open-label, randomised, multicentre phase 2 trial. Lancet; 2013, 381: 2100-07.

14- Degasperi E, Aghemo A. Sofosbuvir for the treatment of chronic hepatitis C: between current evidence and future perspectives. Hepat Med.; 2014, 6: 25-33 (the NEUTRINO study). 
15- El-Khayat H, Fouad Y, Maher M, El-Amin H, Muhammed H. Efficacy and safety of sofosbuvir plus simeprevir therapy in Egyptian patients with chronic hepatitis C: a real-world experience. Gut; 2016, 0:1-5.

16- El Raziky M, Gamil M, Ashour M.K, Sameea EA, Doss W, Hamada Y, et al. Simeprevir plus sofosbuvir for eight or 12 weeks in treatmentnaïve and treatment-experienced hepatitis $\mathrm{C}$ virus genotype 4 patients with or without cirrhosis. $J$ Viral Hepat.; 2017, 1-9.
17- Eletreby R, Elakel W, Said M, El Kassas M, Seif S, Elbaz T, et al. Real life Egyptian experience of efficacy and safety of Simeprevir\ Sofosbuvir therapy in 6211 chronic HCV genotype IV infected patients, Liver international: official journal of the International Association for the Study of the Liver. Liver international; 2017, 1-8.

18- Kwo P, Gitlin N, Nahass R, Bernstein D, Etzkorn K, Rojter S, et al. Simeprevir plus sofosbuvir (12 and 8 Weeks) in hepatitis $\mathrm{C}$ virus genotype 1infected patients without cirrhosis: OPTIMIST-1, a phase 3, randomized study, Hepatology; 2016, 64(2): 1-11. 